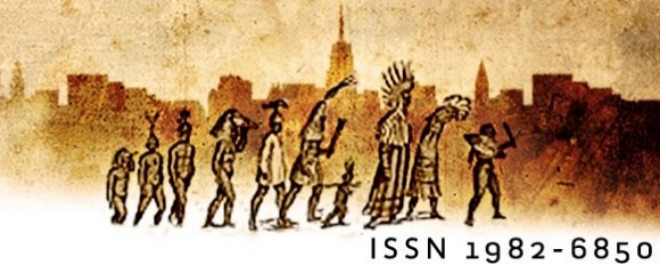

\title{
O programa de linguística geral no manuscrito Hacia una lingüística integral (Por uma linguística integral) de Eugenio Coseriu
}

\section{The general linguistics programme in the manuscript Hacia una lingüística integral (Towards an integral linguistics) by Eugenio Coseriu}

Clemilton Lopes Pinheiro' (UFRN) Sílvio Luis da Silvaii (UFPB)

Resumo: Este trabalho dedica-se à recensão do manuscrito Hacia una lingüística integral (Por uma linguística integral) de Eugenio Coseriu, que constitui a transcrição de um curso que o linguista ministrou na Universidade Autônoma do México, em 1975. O manuscrito mobiliza uma série de temas, definições e problemas de forma a compor uma unidade e a apresentar as distinções básicas que fundamentam a tarefa de uma linguística integral: a linguística que deve dar conta dos diferentes aspectos envolvidos no complexo funcionamento da linguagem com base em um marco homogêneo e unitário.

Palavras-chave: História da Linguística; Linguística coseriana; Linguística integral.

Abstract: This work brings up an overview of the manuscript Hacia una linguística integral (Towards an Integral Linguistics) by Eugenio Coseriu, which is the transcription of a course he has taught at the Autonomous University of Mexico in 1975. The manuscript gathers a series of themes, definitions and problems in a way it creates a unit and presents the basic distinctions that underlie Integral Linguistics tasks: a Linguistics that must embrace the different aspects involved in the language complex 
functioning based upon a homogeneous and unitary framework.

Keywords: Historical Linguistics; Coserian Linguistics; Integral Linguistics.

\section{Introdução}

O conjunto da obra de Eugenio Coseriu abrange quase todas as subáreas da Linguística: filosofia da linguagem, teoria gramatical, semântica, linguística de texto, dialetologia, estilística, tradução, política linguística, história da linguística, entre outras. Essa extensão temática é uma manifestação de sua concepção pessoal acerca do que é a linguagem e a própria Linguística. A proposta de Coseriu visava compreender toda a realidade da linguagem e integrá-la sistematicamente em um modelo epistemológico funcional ${ }^{1}$.

Segundo Kabatek (2004), Coseriu é frequetemente visto como um puro estruturalista, porque boa parte de sua obra fundamental, principalmente a dos anos 1950, provém de um confronto com as ideias de Ferdinand de Saussure (as ideias presentes no Curso de Linguística Geral, talvez seja bom frisar). No entanto, Kabatek assinala que os trabalhos de Coseriu sempre seguiram dois tipos de objetivos: "De um lado, o de levar a sério a linguística estruturalista em toda sua extensão, ou seja, recobrir todos os domínios da língua; de outro lado, o de mostrar seus limites" (KABATEK, 2004, p, 487).

De fato, Coseriu (1982) defende a necessidade de ir além do Estruturalismo. Para ele, "ir além" não quer dizer abolir, mas reconhecer tudo o que há de válido como ponto de vista, como conceito e resultados positivos, no que diz respeito ao conhecimento da linguagem e das línguas, e reintegrar tudo o que ele exclui. "Trata-se de dar conta de toda a competência do sujeito linguístico, de todo o conhecimento que esse sujeito usa no momento em que fala" (COSERIU, 1982, p. 168). Nesse sentido, Coseriu aponta para a perspectiva de uma linguística integral, ou seja, uma linguística que admite diferentes pontos de vista acerca do mesmo problema. A ideia de uma

\footnotetext{
${ }^{1}$ A obra coseriana, que reúne uma enorme quantidade de manuscritos, muitos inéditos, se encontra reunida no Arquivo Eugenio Coseriu na Universidade de Tübingen, Alemanha (http://www.coseriu.de).
} 
linguística integral foi citada por Coseriu, em alguns trabalhos, sobretudo quando se posicionava sobre o papel das diferentes áreas da Linguística.

Em um curso que ministrou na Universidade Autônoma do México (UNAM), entre setembro e outubro de 1975, Coseriu explorou de forma sistemática essa questão e refletiu sobre a maneira de integrar os diferentes aspectos da linguagem e as principais correntes teóricas da Linguística da época. O curso foi gravado e transcrito. A transcrição compõe o manuscrito intitulado Hacia una lingüística integral (Por uma linguística integral), que se encontra no arquivo de Coseriu, na Universidade de Tübingen. Esse manuscrito, a nosso ver, apresenta de forma bastante esquemática a configuração da teoria coseriana de linguagem, que, talvez, não se encontre textualizada dessa forma em nenhum outro lugar. Embora grande parte dos assuntos, aspectos, problemas e o próprio marco geral da sua teoria tenham sido explorados em diversas outras obras da sua vasta produção, nesse material, em especial, Coseriu mobiliza tudo isso de forma a compor uma unidade e a apresentar as distinções básicas que fundamentam a tarefa de uma linguística integral. Este trabalho dedica-se à recensão desse manuscrito.

\section{Apresentação do manuscrito}

Como já dissemos, o manuscrito Hacia uma lingüística integral é a transcrição de um curso ministrado por Eugenio Coseriu na Universidade Autônoma do México. Não há muitas informações que ajudem a recuperar a história desse curso. No Arquivo de Coseriu, há um recorte de um informe publicado, no número 10, volume XI, 1975, da Gazeta UNAM, órgão informativo da UNAM, em que se dá notícia do curso:

Os pesquisadores do Centro de Estudos Clássicos do Instituto de Investigações Filológicas assistiram a um curso, no período de 22 de setembro a 17 de outubro, ministrado pelo Doutor Eugenio Coseriu, eminente linguista da Universidade de Tübingen, Alemanha.

Através de mensagem eletrônica trocada entre o professor Johannes Kabatek ${ }^{2}$ e professora Claudia Parodi, uma das ouvintes, sabemos que o curso foi organizado pelo professor Juan Lope Blanch, então coordenador do Centro de Linguística

\footnotetext{
2 O próprio professor Johannes Kabatek generosamente compartilhou conosco a mensagem eletrônica que trocou com a professora Claudia Parodi, infelizmente, já falecida.
} 
Hispânica da UNAM. Segundo a professora, as aulas foram eminentemente expositivas e não foi apresentado plano de curso, bibliografia nem outro tipo de material adicional. Os nove alunos que assistiram ao curso (Marcela Uribe, Juan López Chavez, Elizabeth Luna, Cecilia Rojas, Antonio Millán, Carlos Cervantes, Antonio Alcalá, Claudia Parodi, Jose Moreno de Alba) foram também encarregados de realizar as transcrições das gravações das aulas.

A professora Cecilia Rojas, em uma conversa, nos falou comovida sobre a lembrança que guarda das aulas e do estilo de Coseriu. Segundo ela, a meta original era publicar as transcrições das aulas em livro. Essa tarefa não parecia difícil, porque o discurso de Coseriu era tão estruturado como sua escrita. No entanto, a ideia não foi levada a cabo. As transcrições e as gravações foram guardadas por Juan Lope Blanch, que, posteriormente, enviou as transcrições ao próprio Coseriu.

O manuscrito está datilografado e encontra-se organizado em doze partes (numeradas de I a XII) relativas a cada uma das doze sessões/conferências do curso. A maioria dessas partes está identificada apenas pelo número, mas algumas trazem como título a ordem da sessão/conferência ou a data: "segunda sessão", "sétima conferência", "conferência ministrada pelo Doutor Eugenio Coseriu, sexta-feira, 10 de outubro de 1975". A transcrição segue as convenções da escrita, no caso, as convenções do espanhol (ortografia, pontuação, organização sintática). Nesse sentido, diríamos que não se trata apenas de uma transcrição como imagem de uma realidade sonora, mas de uma transposição ou retextualização da fala para a escrita (MARCUSCHI, 2010).

Há algumas rasuras, produzidas à mão, no manuscrito, indicativas de correções no que diz respeito às convenções da escrita, e algumas pequenas e raras correções de conteúdo. Isso indica que o manuscrito foi revisado, portanto, pode-se pensar que não apresenta mudanças consideráveis no que diz respeito ao teor do que foi dito na fala. No trecho da Figura 01, por exemplo, observamos algumas rasuras que indicam correções no que diz respeito a convenções da escrita: a letra maiúscula, o emprego de dois pontos e aspas em "En el caso entonces de 'César venció a Pompeyo'" (No caso então de "César venceu Pompeu"). No trecho da Figura 02, por outro lado, observamos o acréscimo de uma informação: "así que no les encuentram ustedes em los libros sobre lingüística funcional" (de modo que vocês não encontram isso nos livros de linguística funcional). 
As1, por ejemplo, en el caso del activo y de su equivalente pasivo, se habla de identidad porque hay identidad de designacion, Een el caso entonces dę̧ "Cêsar venciô a Pompeyo," "Pompeyo fue vencido por Cêsar. "Si se dice por ejemplos" Los tacones son demasiado bajos," pues esto se considera como 10 mismo ques" hos tacones no son bastante altos". Es decir, de nuevo porque la designacion es la misma. O bien en el caso que hemos visto " A es más grande que $B$," $B$ es más pequeño que

Figura 01: Trecho do manuscrito, Conferência XI, p. 1

Los principios de esta lingüfstica son cuatro y precisamente los siguientes:

1) principio de la funcionalidad - principio fundamental

2) principio de las oposiciones distintivas

3) principio de la sistematicidad

4) principio de la neutralizacion

la Estos principios son principios, por asf decir, subyacentes en toda./ lingüistica funcional, normalmente no se enuncian, Gh' que mo ln ln-

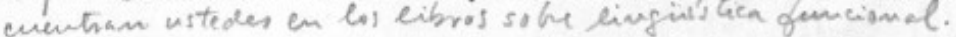

El principio de la funcionalidad significa: existe comunidad

Figura 02: Trecho do manuscrito, Conferência XI, p. 15

No que diz respeito à organização temática, o manuscrito se organiza em torno de seis temas. O primeiro tema são as noções preliminares: as três correntes da Linguística e as quatros teses relacionadas aos três planos da linguagem (universal, histórico e individual). Esse tema é desenvolvido na conferência I. Trata-se, em outras palavras, da apresentação do "esquema geral" do curso. Por correntes da Linguística, Coseriu entende a Linguística Estrutural e Funcional, a Gramática Gerativa e a Linguística do Texto:

O que entendo por correntes características da Linguística? Entendo que são, pelo menos, três, que efetivamente se apresentam como concepções diferentes e se apresentam também com aspiração de abarcar a linguagem e de esclarecer tudo a partir de certo ponto de vista, que é particular a cada uma delas. Essas correntes são a Linguística Estrutural e Funcional, que, de uma certa forma, podemos 
dizer, ao menos teoricamente, abarca também a Linguística tradicional, na medida em que, pelo menos, no que ela pôde reinterpretar-se em termos estruturais e funcionais; a Gramática Gerativa e Transformacional; e, uma orientação que considero essencial, a Linguística do Texto³. (Conferência I, p. 6)

As teses assumidas em relação aos três planos da linguagem são as seguintes:

1. Existem funções linguísticas próprias de cada nível: funções do falar em geral, funções de uma língua determinada, que, em outra língua, podem faltar, podem se expressar em outras funções mais amplas ou podem ser divididas em várias, e existem funções do texto.

2. Há tipos de conteúdo próprios para cada plano: a) designação, conteúdo próprio do plano do falar; b) significação, conteúdo próprio do plano das línguas; c) sentido, conteúdo próprio do plano do discurso ou texto.

3. Cada orientação da Linguística deve corresponder, em essência, a um dos três planos, e, portanto, a cada uma das três séries de funções e cada um dos três tipos de conteúdo.

4. Os projetos dessas orientações da Linguística são complementares: descrição onomasiológica (Linguística do falar), descrição semasiológica (Linguística das línguas), e hermenêutica do sentido (Linguística do Texto).

O segundo tema são os três planos da linguagem: o plano do falar em geral, desenvolvido na conferência II; o plano do texto, desenvolvido na conferência III; e o

\footnotetext{
3 Quando fala de funcionalismo, Coseriu, como ele mesmo explica, se refere à abordagem do plano do sistema funcional, das oposições funcionais da própria língua. Evidentemente, Coseriu não trata da corrente funcionalista atual, em suas diferentes versões, que concebe função como o uso das expressões linguísticas na interação verbal (NEVES, 1994). Quando trata de "gramática gerativa e transformacional", Coseriu parte da compreensão que, no momento, ele tinha sobre o desenvolvimento da teoria linguística conhecida hoje genericamente como Gramática Gerativa. Depois disso, a teoria passou por outros desenvolvimentos (BORGES NETO, 2004; SILVA E COSTA, 2004). Da mesma forma, Coseriu recupera o percurso de estudos sobre o texto do momento. Depois disso, segundo o próprio Coseriu (2007), a Linguística do Texto se desenvolveu em uma direção completamente distinta da que ele havia esboçado. De fato, a partir da segunda metade dos anos 1970, nessa direção distinta, a Linguística do Texto começou a aparecer como tal em vários trabalhos independentes entre si, na Europa ocidental, notadamente em países como Alemanha e França. A partir daí, se observa uma explosão de estudos textuais, não apenas em número de praticantes e publicações, mas em diversidade de modelos e teorias. Hoje, depois de quase meio século de estudos, já se encontra plenamente institucionalizada como área (Koch, 2004). No início da década de 1980, o pensamento de Coseriu sobre o texto foi apresentado na obra Textlinguistik. Eine Einführung, editada por Jörn Albrecht (COSERIU, 1980), a partir de um curso ministrado na Universidade de Tübingen. O livro foi traduzido para o italiano (COSERIU, 1997) e para o espanhol (COSERIU, 2007).
} 
plano das línguas, desenvolvido nas conferências IV, V e em parte da VI. Aqui é feita de forma sistemática a distinção entre os planos"

O que são os planos da linguagem? O que entendemos por plano do falar em geral, plano das línguas e plano do discurso? Vejamos, também, mais de perto, os fundamentos dessa distinção: por que distinguimos esses três planos, e por que é necessário fazê-lo?

A linguagem é uma atividade universal, ou seja, todos os seres humanos normais falam. É uma atividade humana universal realizada por cada ser humano individualmente, mas, ao mesmo tempo, como membro de uma comunidade histórica. Nessa descrição ou nessa caracterização já estão contidos os três planos: atividade humana universal, que se realiza por cada pessoa individualmente. Em outras palavras, a linguagem não é uma atividade coral. Mesmo no diálogo, cada um fala por conta própria. Mesmo ao falar com outro, também individualmente, cada um fala como membro de uma comunidade historicamente estabelecida, ou seja, a linguagem se apresenta sempre sob a forma de tradições idiomáticas, sempre sob forma de língua. (Conferência I, p. 22)

O terceiro tema são as funções linguísticas de cada plano. Esse tema apresenta dois desdobramentos: a organização das funções nas diferentes línguas (conferência VI) e a tarefa de distinguir as funções: funções do falar em geral, funções da língua e funções do texto (conferência VII). Esse tema é para Coseriu o ponto mais difícil e inédito do curso.

Já disse também que é o ponto mais difícil, porque todos tendem a confundir essas funções, porque se dão conjuntamente, é claro, nos textos, nos discursos, e porque a tradição, nesse caso, ajuda pouco, dado que não é normal, comum a distinção de funções. Quando falamos de funções de língua, entendemos sempre as funções em uma determinada tradição e no nível que chamamos de sistema da língua. A grande dificuldade é, principalmente, a distinção dessas funções idiomáticas. Estamos todos tão dominados pelas funções do falar em geral, pelo conteúdo do pensamento que queremos transmitir, comunicar, e pelas funções do texto, que não percebemos, na realidade, o que é efetivamente função de língua, ou seja, aquilo que a língua como tal diz e o que sabemos, precisamente, porque conhecemos uma determinada língua. (Conferência VII, p. 1)

A função do falar em geral é a de referir a uma realidade extralinguística, ou seja, a realidade do mundo, a função da língua é ser o instrumento particular para a organização do real ou para a manifestação dos propósitos do discurso, e a função do texto é o propósito de um discurso particular, que ocorre em uma situação determinada

\footnotetext{
${ }^{4}$ As citações do manuscrito foram traduzidas por nós mesmos. Faremos referência ao número da conferência e à página.
} 
e única. A distinção entre a velhice das coisas e a velhice das pessoas, por exemplo, é uma função do falar em geral, ou seja, é dada pelo conhecimento das coisas. A língua portuguesa não faz essa distinção e se diz "uma pessoa velha", "um cachorro velho" e "uma casa velha", o que quer dizer que não há, nesse caso, uma função da língua, porque esse conteúdo não é dado pela língua. No latim, por outro lado, a situação é outra, e existem formas diferentes para cada conteúdo: sedex para pessoa (homem sedex - homem velho), vetulus para animal (canis vetulus - cachorro velho) e vetula para coisa (pinus vetula - pinheiro velho). Em resumo, a distinção entre a velhice das pessoas, dos animais e das coisas é uma função do latim, mas não é da língua portuguesa.

Da mesma forma, há funções do texto que podem ser funções de alguma língua, mas não de outra, ou mesmo funções do texto que não são expressas por nenhuma língua. Coseriu usa o exemplo da pergunta, que é uma função do texto e não da língua.

A própria pergunta, por exemplo, como função do texto pode ser expressa de outra maneira além de uma oração interrogativa. Pode ser a chamada interrogativa indireta, caso em que já não se faz a pergunta, ou outros procedimentos, como no caso em que se diz a alguém será melhor que você me conte tudo), ou seja, não há oração interrogativa, mas trata-se de uma maneira de perguntar. (Conferência VII, p. 16)

Os tipos de conteúdo de cada plano é o quarto tema, desenvolvido na conferência VIII. Nesse ponto, é explorada a circunstância de que todo fato linguístico tem um conteúdo.

A distinção desses planos assim como das funções específicas para cada um não teria um fundamento sólido se não fosse ao mesmo tempo uma distinção sobre o que constitui a funcionalidade da linguagem, ou seja, o conteúdo que se expressa, se manifesta ou se comunica. Trata-se, na verdade, de três tipos diferentes de conteúdo: designação, significado e sentido. (Conferência VIII, p. 2)

A relação entre os planos da linguagem e as correntes da Linguística é o quinto tema, que se desdobra em três: Linguística do Texto e o plano individual (conferência IX), Gramática Gerativa e o plano do falar em geral (parte da conferência IX e conferência X), Linguística Estrutural e Funcional e o plano histórico (conferência XI e parte da conferência XII). O último tema é a complementariedade dos enfoques, desenvolvido na parte final da conferência XII. A ideia defendida nessas três últimas partes é, em resumo, a de que as questões de linguagem que podem ser 
discutidas/resolvidas com base em um enfoque não podem ser com base em outros. Essa é também a ideia base de uma linguística integral.

\section{A proposta teórica no manuscrito: uma linguística integral}

O manuscrito Hacia una lingüística integral traz, talvez, uma das primeiras definições de linguística integral: a linguística que deve dar conta dos diferentes aspectos envolvidos no complexo funcionamento da linguagem com base em um marco homogêneo e unitário. Essa perspectiva de linguística integral foi retomada algumas outras vezes por Coseriu, anos mais tarde, conforme mostram as duas citações a seguir.

Assim o primeiro [problema] para a linguística integral é recuperar a Linguística do falar ao lado da Linguística das línguas, já bem conhecida. Praticamente toda ou quase toda a Linguística Tradicional e a moderna se apresenta como Linguística das línguas. Está claro que, tendo se assumido que há também um saber que se refere ao plano individual próprio dos textos, devemos ter ao lado da Linguística das Línguas, uma Linguística do discurso ou do texto. Em uma Linguística Integral, esses dois planos da linguagem devem ser recuperados: o do falar em geral e o do discurso ou do texto. Mas no plano histórico como tal, no plano mesmo das línguas, concentrar-se na língua funcional, ou seja, em um sistema linguístico homogêneo, indica toda uma série de discussões que, portanto, implica para a linguística integral a necessidade de recuperar todo o que se exclui (COSERIU, 1982a, p. 36).

O que é linguística integral? É aquela linguística que se propõe a dar conta do saber que o falante mobiliza quando fala e ordenar os fatos comprovados a esse respeito em um marco homogêneo e unitário. (COSERIU, 1984, p. 37)

Coseriu também falou da linguística integral em entrevistas, como a concedida a Johannes Kabatek e Adolfo Murguía, na Universidade de Tübingen (Kabatek; Murguía, 1997). Na entrevista, Adolfo Murguía pergunta a Coseriu, por exemplo, se ele aceita o termo linguística integral para sua teoria. Ele confirma e justifica com base no pressuposto básico que estabeleceu para a pesquisa linguística: o de que a linguagem apresenta três níveis autônomos: o nível universal ou nível do falar em geral, o nível histórico das línguas, o nível individual dos textos. 
Esses três planos funcionam, conjuntamente, em todo ato de fala: o nível da fala em geral, que vale para qualquer língua, o nível das línguas, que se refere à organização de uma língua determinada, e, de alguma forma, de uma língua histórica, e o nível do texto. Cada um desses níveis tem sua autonomia, suas próprias funções, e, o mais importante, um tipo de conteúdo próprio: designação, significado e sentido. As funções e os conteúdos de cada nível constituem de um tipo de saber: elocucional, idiomático e expressivo, respectivamente. Disso decorre a existência de três orientações para a linguística, que correspondem, em essência, a cada um dos três planos, funções e conteúdos. Assim, há a linguística que corresponde ao plano do falar, às funções do falar e à designação. A linguística que corresponde ao plano histórico das línguas, às funções próprias das línguas, e ao significado. E, por fim, a linguística que corresponde ao plano do texto, ao sentido. Esse é o marco homogêneo e unitário da linguística integral desenhado no manuscrito. O quadro 01 sintetiza esse marco.

\begin{tabular}{|l|l|l|l|l|}
\hline Nível & Saber & Atividade & Conteúdo & Linguística \\
\hline Universal & Elocucional & Falar em geral & Designação & Do falar \\
\hline Histórico & Idiomático & $\begin{array}{l}\text { Falar língua } \\
\text { uma } \\
\text { concreta }\end{array}$ & Significado & Das línguas \\
\hline Individual & Expressivo & Falar textos & Sentido & Do texto \\
\hline
\end{tabular}

Quadro 01: Marco da linguística integral

Cada linha do quadro corresponde a um conjunto de aspectos da linguagem, que, sendo de natureza distinta, constitui o objeto particular de uma linguística cujos métodos e técnicas servem apenas para a descrição e interpretação desse objeto em particular. Cada linguística apresenta, portanto, seus problemas específicos e seu respectivo instrumental analítico, e uma não pode resolver os problemas de outra. $\mathrm{A}$ linguística integral é, nesse sentido, a ciência da linguagem em toda a sua dimensão, e comporta cada uma dessas linguísticas com seus respectivos pontos de vista.

A linguística do falar (que pode também ser chamada de Gramática da Fala, Gramática da Designação ou Gramática Onomasiológica) tem como objeto o saber que não é idiomático e que não pertence a uma nenhuma língua determinada, o saber elocucional, e o seu ponto de vista é o da designação. A tarefa dessa é linguística é a de 
distinguir as funções do falar, que dizem respeito aos elementos da realidade, e suas relações. O agente (o que está ativo em uma ação), por exemplo, pode ser tomado como uma função do falar (um conteúdo do pensamento). Esta função pode se manifestar em diferentes expressões de uma língua. Em português, por exemplo, pode ser "César venceu Pompeu", "Pompeu foi vencido por César", "a vitória de César". Nos três casos, "César" é o agente da vitória (a designação é a mesma), e as diferenças na expressão dizem respeito a funções de língua. "O agente, então, é um tipo de função que deve ser distinguida de uma possível função em uma língua, que poderíamos chamar de agentivo, isto é, uma função de língua específica para expressar o agente" (Conferência VII, p. 9).

Uma língua pode, portanto, ter uma função determinada para uma função do falar em geral, pode incluir diferentes funções do falar e diferentes conteúdos do pensamento, identificáveis como tal, sob uma única função mais geral, pode não expressar uma categoria do falar e simplesmente deixar que isso seja entendido pelo contexto ou pela situação, pode ter certas categorias, mas não usar sempre nos mesmos casos. Por isso, é necessário distinguir e identificar as funções do falar. Tratase de uma tarefa, em grande parte, ainda aberta.

Infelizmente, não temos, ainda, nem mesmo os termos para distinguir, em cada caso, as funções do falar. Essas funções são provavelmente como as espécies lógicas de Leibniz das quais já falamos, na realidade, infinitas. Podem ser infinitas, pelo menos, dentro de certas categorias, que podem continuar fazendo distinções. Essas distinções, aliás, podem ser distinguidas no falar, mesmo quando não constituem funções de língua. Na maioria dos casos, os termos que temos são aplicados de maneira indistinta tanto para o falar quanto para a língua, exceto, talvez, um termo como sujeito que se aplica apenas a um fato de língua. Quando se fala sobre sujeito, por exemplo, alguns distinguem um sujeito lógico, que seria precisamente a categoria agente do pensamento ou do falar em geral. (Conferência VII, p. 13)

A linguística das línguas é radicalmente diferente da linguística do falar em geral, porque seu interesse é a forma como uma língua em particular é constituída, os seus paradigmas funcionais, o conteúdo que é distinguido por ela própria tanto na gramática como no léxico. A tarefa dessa linguística consiste, portanto, em identificar os significados de uma língua com base nas relações opositivas que se estabelecem 
entre eles. Considera-se, nesse caso, o princípio segundo o qual, em uma língua, a cada expressão (significante) corresponde um significado.

\begin{abstract}
A ideia aqui é a de que existe uma correspondência na língua entre significante e significado, em todos os níveis, tanto léxico como na gramática. O significado é simplesmente a outra parte do signo, o significante, e significado e significante são faces do signo. Com base nisso, afirma-se que existe significado apenas se existir significante; $e_{\text {, }}$ ao contrário, existe significante, como unidade, apenas se também houver um significado específico para tal significante. Dito de outro modo: a ideia fundamental em que se baseia o método é a dupla solidariedade entre significante e significado. (Conferência XI, p. 123)
\end{abstract}

Em resumo, a linguística da língua se preocupa em encontrar e comprovar os paradigmas que funcionam nos diversos estratos da estruturação gramatical de uma língua (paradigmas das palavras, dos grupos de palavras, da oração, e, inclusive, do texto, aqui entendido como nível de estruturação gramatical). Em português, por exemplo, "canta" quer dizer "canta" (com traço iterativo) ou "canta uma vez" (com traço semelfactivo). No entanto, não se trata de uma distinção funcional (nem semelfactivo nem iterativo são unidades de significado do português), porque o significante "canta" não muda.

Embora o texto se expresse em uma língua (um idioma), ele não é inteiramente idiomático, e as funções idiomáticas como tais nunca se apresentam nos textos. Da mesma forma, há múltiplas designações em um só sentido e muitos sentidos em várias designações, e a designação não pode aparecer, quando se mantém o sentido como unidade. A linguística do texto abarca esse aspecto da linguagem, o sentido (aquilo que se diz e se entende além da designação e do significado), que não está no falar em geral nem nas línguas, mas no texto, entendido como "o ato linguístico de um falante em uma situação determinada, ou a série de atos conexos de um indivíduo, de um falante" (Conferência II, p. 25).

Como já disse, as indagações sobre o sentido são feitas após o entendimento de algo em termos de designação e significado. Se alguém diz, por exemplo, "Bem, se este for o caso, não conte comigo", e outro alguém responde "O que você quer dizer com isso?", é evidente que houve compreensão sobre o que foi dito (não conte 
comigo), mas a pergunta é posta sobre o sentido, isto é, sobre certas conexões, certas intenções, sobre o propósito. (Conferência VII, p. 11)

A tarefa da linguística do texto é, portanto, estudar as macro e microestruturas do texto, seja um fato gramatical, lexical ou de designação, que podem contribuir para o sentido. Essa tarefa consiste, fundamentalmente, em mostrar os tipos, os procedimentos de busca e a forma como se manifesta o sentido.

O quadro aqui desenhado, o da linguística integral, com base na leitura do manuscrito, se configura, em resumo, como uma proposta de linguística geral, "altamente séria e de grande envergadura, que propõe uma espécie de marco geral para a investigação linguística e para o desenvolvimento de uma consciência sobre o lugar e a relação de cada disciplina no conjunto das disciplinas" (KABATEK, 2003, p. 98).

\section{Considerações finais}

Um dos principais pressupostos do pensamento de Eugenio Coseriu sobre a linguagem é o de que o falar é uma atividade muito mais complexa que a realização de uma língua. O curso que ministrou na Universidade Autônoma do México, em 1975, cuja transcrição constitui o manuscrito Hacia una lingüística integral toma como base esse pressuposto e suas consequências, e, a partir daí, apresenta uma sólida unidade de pensamento, que caracteriza, em última análise, todo o conjunto da sua obra. Os temas das principais publicações de Coseriu estão contemplados no manuscrito de forma que algumas das suas principais publicações poderiam ser apontadas como uma bibliografia de referência.

O célebre ensaio Determinación y entorno, de 1955, publicado em Coseriu (1967) traz pela primeira vez a distinção entre linguística do falar, linguística das línguas e linguística do texto. Os artigos Introducción al estudio estrutural del léxico e Designación y significados a la luz de la Semântica Estrutural, publicados em Coseriu (1977a), fazem as distinções prévias do enfoque estruturalista para então fundamentar o estudo da designação e do significado à luz da semântica estrutural. A situação e o desenvolvimento da Linguística são temas de dois capítulos de Coseriu (1977). Igualmente, em Coseriu (1980a) são desenvolvidos conceitos básicos como o de língua 
funcional, sistema, norma e falar concreto, assim como a retomada da distinção entre os três níveis da linguagem e as disciplinas linguísticas relacionadas a cada um dos níveis. Especificamente sobre linguística integral e linguítica do texto, cite-se Coseriu (1984) e (2007), respectivamente.

Esse brevíssimo levamento de obras, de épocas diferentes, umas antigas, outras mais recentes, cujos temas estão presentes no manuscrito, mostra que a linguistica integral é uma perspectiva teórica fundada em uma visão coerente e unitária de linguagem, que caracteriza o edifício fundamental do pensamento de Eugenio Coseriu. O manuscrito Hacia uma lingüística integral é uma forma de acesso a esse edifício, mas pode ser também um dispositivo de transmissão da obra de Coseriu e de estímulo à pesquisa linguística das futuras gerações.

\section{Referências}

BORGES NETO, José. O empreendimento gerativo. In: MUSSALIM, Fernanda; BENTES, Anna Christina (Org.). Introdução à linguística - fundamentos epistemológicos. São Paulo: Cortez, 2004, p. 93-129.

COSERIU, Eugenio. Teoría del lenguaje y lingüística general. Madrid: Gredos 1967.

COSERIU, Eugenio. El hombre y su lenguaje. Madrid: Gredos 1977.

COSERIU, Eugenio. Principios de Semántica Estructural. Madrid: Gredos, 1977a.

COSERIU, Eugenio. Textlinguistik: Eine Einführung. Hrsg und beab. Von Jörn Albrecht. Tübingen: Francke, 1980.

COSERIU, Eugenio. Liçoes de linguística geral. Rio de Janeiro: Ao Livro Técnico, 1980a.

COSERIU, Eugenio. Au délà du structuralisme. Actes, XVI Congrés Internacional de Lingüística Filologia Romàniques. Palma de Mallorca: Editorial Moll, 1982, p. 163-168.

COSERIU, Eugenio. Mas alla del estructuralismo. San Juan: Facultad de Filosofía, Humanidade y Artes/Universidad Nacional de San Juan, 1982a.

COSERIU, Eugenio. Fundamentos y tareas de la lingüística integral. Actas del Segundo Congreso Nacional de Lingüística, Universidad Nacional de San Juan, Argentina, 1984, p. 37-53.

COSERIU, Eugenio. Linguistica del testo: Introduzione a una ermeneutica del senso. Edizione italiana a cura di Donatella Di Cesare. Roma: Caroci editore, 1997. 
COSERIU, Eugenio. Lingüística del texto. Introducción a la hermenéutica del sentido (édition et annotation d'Oscar Loureda Lamas). Madrid: Arco/Libros, 2007.

KABATEK, Johannes; MURGUÍA, Adolfo: "Die Sachen sagen, wie sie sind..." Eugenio Coseriu im Gespräch. Tübingen: Gunter Narr 1997.

KABATEK, Johannes. Unidad del significado, designado y linguística integral. Odisea, n. 3, 2003, p. 87-99.

KABATEK, Johannes. Eugenio Coseriu (1921-2002). Estudis Romànics. Vol. 26, 2004, p. 484-488.

$\mathrm{KOCH}$, Ingedore Villaça. Introdução à linguística textual: trajetória e grandes temas. Contexto, São Paulo, 2004.

MARCUSCHI, Luís Antônio. Da fala para a escrita: atividades de retextualização. 10. ed. São Paulo: Cortez, 2010.

NEVES, Maria Helena de Moura. Uma visão geral da gramática funcional. Alfa, n. 38, 1994, p. 109-127.

SILVA, Maria C. Figueiredo; COSTA, João. Os anos 1990 na gramática gerativa. In: MUSSALIM, Fernanda; BENTES, Anna Christina (Org.). Introdução à linguística fundamentos epistemológicos. São Paulo: Cortez, 2004, 131-218.

\footnotetext{
' Doutor em Letras, área de Filologia e Linguística Portuguesa. Professor de Linguística do Departamento de Letras e do Programa de Pós-Graduação em Estudos da Linguagem da Universidade Federal do Rio Grande do Norte (UFRN).

ORCID: https://orcid.org/0000-0003-4285-9932.

E-mail: clemiltonpinheiro@hotmail.com.

ii Doutor em Estudos da Linguagem. Professor de Língua Portuguesa e Linguística do Departamento de Letras, Centro de Ciências Aplicadas e Educação da Universidade Federal da Paraíba (UFPB) - campus IV.

ORCID: https://orcid.org/0000-0002-1004-4643.

E-mail: silviodasilva@gmail.com.
}

Recebido em 03/11/21

Aprovado em 11/12/21

Todo conteúdo da Revista Eutomia está sob a Licença Creative Commons Atribuição 4.0 Internacional. 